\title{
Atypical Lobular Breast Hyperplasia
}

National Cancer Institute

\section{Source}

National Cancer Institute. Atypical Lobular Breast Hyperplasia. NCI Thesaurus. Code C4730.

Lobular neoplasia characterized by lobular epithelial proliferation that does not completely fill the lobular unit of the breast. 